\title{
Distortion of maternal-fetal angiotensin II type 1 receptor allele transmission in pre-eclampsia
}

\author{
L Morgan, S Crawshaw, P N Baker, J F Y Brookfield, F Broughton Pipkin, N Kalsheker
}

\begin{abstract}
Objective-To investigate the fetal angiotensin II type 1 receptor genotype in preeclampsia.

Design-Case-control study.

Population-Forty-one maternal-fetal pairs from pre-eclamptic pregnancies and 80 maternal-fetal pairs from normotensive pregnancies.

Methods-Maternal and fetal DNA was genotyped at three diallelic polymorphisms, at nucleotides 573, 1062, and 1166, in the coding exon of the angiotensin II type 1 receptor gene, and at a dinucleotide repeat polymorphism in its $3^{\prime}$ flanking region.
\end{abstract}

Results-Allele and genotype frequencies at the four polymorphic regions investigated did not differ between pre-eclamptic and normotensive groups, in either fetal or maternal samples. Mothers heterozygous for the dinucleotide repeat allele designated A4 transmitted this allele to the fetus in 15 of 18 informative preeclamptic pregnancies and in eight of 26 normotensive pregnancies. This was greater than the expected probability in pre-eclamptic pregnancies $(p=0.04)$ and less than expected in normotensive pregnancies $(p<0.005)$. The $573 T$ variant, which is in partial linkage disequilibrium with the A4 allele, showed a similar distortion of maternal-fetal transmission. Conclusion-Angiotensin II type 1 receptor gene expression in the fetus may contribute to the aetiology of preeclampsia. It is unclear whether susceptibility is conferred by the fetal genotype acting alone, or by allele sharing by mother and fetus. Possible mechanisms for the effect of the angiotensin II type 1 receptor gene are suggested by the association of the 573T variant with low levels of surface receptor expression on platelets. If receptor expression is similarly genetically determined in the placenta, responsiveness to angiotensin II may be affected, with the potential to influence placentation or placental prostaglandin secretion. $(F$ Med Genet 1998;35:632-636)

Keywords: pre-eclampsia; angiotensin II type 1 receptor

It is widely recognised that pre-eclampsia, the severe proteinuric form of pregnancy induced hypertension, has an inherited component. ${ }^{1}$ The model of inheritance has not been defined; in particular, the contribution of the fetal genotype is unclear. Epidemiological studies are consistent with dominant maternal inheritance with partial penetrance ${ }^{2}$ and fetal factors may influence penetrance. Indeed, some epidemiological evidence supports a model of gene sharing between mother and fetus in the aetiology of pre-eclampsia. ${ }^{3}$

Although pre-eclampsia presents clinically in the second half of pregnancy, impaired trophoblastic invasion of the myometrial segment of maternal spiral arteries during early pregnancy is a characteristic feature. ${ }^{4}$ The resulting altered placental haemodynamics and placental ischaemia may be factors in the aetiology of pre-eclampsia. ${ }^{5}$ The placenta is unusual among vascular beds in having no autonomic nerve supply; vascular resistance on the fetal side of the circulation is determined by humoral factors, including angiotensin II (AII), the vasoactive peptide formed by sequential cleavage of angiotensinogen by renin and angiotensin converting enzyme. Angiotensin II receptors with the pharmacological characteristics of type $1\left(\mathrm{AT}_{1}\right)$ receptors have been found in resistance vessels in term placentae ${ }^{6}$ and are presumably encoded by the fetal gene. They are present at decreased density in term placentae from pre-eclamptic pregnancies and from pregnancies complicated by intrauterine growth retardation. ${ }^{7}$ One possible explanation is that hypo-oxygenation stimulates the fetal renin-angiotensin system ${ }^{8}$ and the resulting rise in fetal plasma angiotensin II concentrations downregulates the placental $\mathrm{AT}_{1}$ receptors.

Angiotensin II stimulates placental prostacyclin secretion. ${ }^{9}$ The receptor subtype responsible has yet to be identified in the placenta. However, at least a proportion of the stimulatory effect of angiotensin II on prostaglandin synthesis in porcine vascular smooth muscle was mediated via $\mathrm{AT}_{1}$ receptors. ${ }^{10}$ Impaired secretion of vasodilatory eicosanoids antedates the onset of clinical hypertension in pre-eclampsia ${ }^{11}$ and contributes to the increased maternal pressor responsiveness to infused angiotensin II in this condition. ${ }^{12}$ It is possible that placental $\mathrm{AT}_{1}$ receptor expression influences both placental haemodynamics and maternal systemic haemodynamics through its effects on placental prostaglandin secretion.

In an earlier study comparing women with pre-eclampsia with normotensive pregnant women, we found no significant difference between the two groups of women in the frequency of three diallelic polymorphisms in the coding exon of the $\mathrm{AT}_{1}$ receptor gene, at nucleotides 573, 1062 and 1166 , or in the allele distribution of a dinucleotide repeat polymorphism in its $3^{\prime}$ flanking region. ${ }^{13}$ In this preliminary study, fetal genotyping from these 
Table 1 Oligonucleotide primers used for $A T$, receptor gene amplification

\begin{tabular}{llll}
\hline Primer & Nucleotides & Strand & Sequence \\
\hline ATR1 & 422 to 443 & Sense & 5'-AATGCTTGTAGCCAAAGTCACCT \\
ATR2 & 1458 to 1436 & Antisense & 5'-CCTGTTGCTCCTCTAACGATTTA \\
ATCA1 & 3' FR & GT & 5'-AGGAGAATGTTCCAAGGGACAA \\
ATCA2 & 3' FR & CA & 5'-GTATTCCATGTGAAACAGCTCCA \\
\hline
\end{tabular}

Nucleotides are numbered from the 5' end of the coding exon. 3' FR: 3' flanking region.

pregnancies has been performed to test the hypothesis that the fetal $\mathrm{AT}_{1}$ receptor genotype is associated with pre-eclampsia. Results were examined both for allele association and for evidence of distortion of allele transmission from mother to fetus in pre-eclamptic pregnancies.

\section{Methods}

SUBJECTS AND SAMPLES

Eighty normotensive pregnant women (71 primigravid, nine multigravid) and 41 women with pre-eclampsia (33 primigravid, eight multigravid) were recruited during the second half of pregnancy. The mean (SD) age of normotensive women was 27.8 (4.0) and of women with pre-eclampsia was 28.3 (5.8). All subjects were white. Pre-eclampsia was defined as a diastolic blood pressure exceeding $90 \mathrm{~mm} \mathrm{Hg}$ and a systolic blood pressure exceeding 140 $\mathrm{mm} \mathrm{Hg}$ in a previously normotensive woman, which returned to normal within three months of delivery, and was associated with proteinuria in excess of $300 \mathrm{mg} / \mathrm{l}$ in a 24 hour collection or two pluses on dipstick testing of a random sample. Maternal genotyping was performed on DNA extracted from peripheral venous blood. Fetal DNA was extracted from umbilical venous blood or umbilical cord samples obtained at delivery if possible, or on filter paper blood spots (Guthrie spots) retrieved from the Trent Regional Neonatal Screening Unit archive. Eighteen (44\%) babies born of pre-eclamptic pregnancies and $43(54 \%)$ born of normotensive pregnancies were male; this difference was not statistically significant $(p>0.05)$. All deliveries were singleton live births.

All mothers gave informed consent, on behalf of themselves and their babies, for participation in the study, which was approved by the hospital Ethics Committee.

\section{GENOTYPING AT DIALLELIC POLYMORPHISMS}

A $1 \mathrm{~kb}$ fragment of the coding exon of the $\mathrm{AT}_{1}$ receptor gene, including part of the coding region and approximately 400 bases of the $3^{\prime}$ untranslated region, was amplified by the polymerase chain reaction (PCR). Amplification reactions were carried out in a total volume of $25 \mu \mathrm{l}$, using 100 to $200 \mathrm{ng}$ genomic DNA or $1 \mathrm{~mm}^{2}$ filter paper blood spot, 200 $\mu \mathrm{mol} / 1 \mathrm{dNTPs}, 25 \mathrm{pmol}$ of each primer, 50 $\mathrm{mmol} / 1 \mathrm{KCl}, 10 \mathrm{mmol} / \mathrm{l}$ Tris $\mathrm{HCl}(\mathrm{pH} 9.0)$, $0.1 \%$ Triton X-100, $1.5 \mathrm{mmol} / 1 \mathrm{MgCl}_{2}$, and 1 U Taq polymerase. Primer sequences are shown in table 1 . Samples were overlayed with $20 \mu \mathrm{l}$ of mineral oil, loaded onto a thermal cycler, and denatured at $96^{\circ} \mathrm{C}$ for five minutes, followed by 35 cycles of $94^{\circ} \mathrm{C}$ for 30 seconds, $60^{\circ} \mathrm{C}$ for one minute, and $72^{\circ} \mathrm{C}$ for one minute,
Table 2 Allele specific oligonucleotides used in competitive hybridisation assays

\begin{tabular}{ll}
\hline Polymorphic site & Allele specific oligonucleotides \\
\hline $573 \mathrm{C}$ to $\mathrm{T}$ & 5'-CAACCCT[C or T]CCGATAG \\
$1062 \mathrm{~A}$ to $\mathrm{G}$ & 5'-CCTGCACC[A or G]TGTTTTAG \\
1166 A to C & 5'-AATGAGC[A or C]TTAGCTA \\
\hline
\end{tabular}

with a final 10 minute extension stage at $72^{\circ} \mathrm{C}$. DNA free controls were run with each batch to detect DNA conta mination of reagent solutions.

Subjects were genotyped at three diallelic polymorphisms (573C to T, 1062A to $\mathrm{G}$, and $1166 \mathrm{~A}$ to $\mathrm{C})^{14}$ by competitive allele specific oligonucleotide (ASO) hybridisation. A total of 2 $\mu \mathrm{l}$ (approximately $50 \mathrm{ng}$ ) of each PCR product was denatured in $125 \mu \mathrm{l}$ of $0.2 \mathrm{~N} \mathrm{NaOH} / 2 \times$ SSC and spotted onto duplicate nylon membranes (Hybond $\mathrm{N}^{+}$, Amersham). Oligonucleotides were synthesised corresponding to wild type and mutant sequences at each site (table 2). Each membrane was prehybridised for one hour at $52^{\circ} \mathrm{C}$ in $10 \mathrm{ml} 5 \times \mathrm{SSPE} / 1 \%$ SDS containing $30 \mathrm{pmol}$ of unlabelled oligonucleotide corresponding to wild type or mutant sequence, then hybridised for one hour at $52^{\circ} \mathrm{C}$ in $10 \mathrm{ml} 5 \times \mathrm{SSPE} / 1 \%$ SDS containing $3 \mathrm{pmol}$ of the alternative ${ }^{32} \mathrm{P}$ end labelled ASO. Membranes were washed in $2 \times \mathrm{SSPE} / 0.1 \% \mathrm{SDS}$ for two 30 minute periods at room temperature, then for 15 minutes in $5 \times \mathrm{SSPE} / 0.1 \% \mathrm{SDS}$ at $52^{\circ} \mathrm{C}$, and autoradiographed at $-70^{\circ} \mathrm{C}$ for 16 hours. Genotyping was confirmed by sequencing at least one sample of each genotype detected.

DINUCLEOTIDE REPEAT POLYMORPHISM

Subjects were genotyped at the dinucleotide repeat polymorphism $(\mathrm{CA})_{\mathrm{n}}$ in the $3^{\prime}$ flanking region of the $\mathrm{AT}_{1}$ receptor gene by electrophoresis of radiolabelled PCR products on denaturing polyacrylamide gels using the primers shown in table $1 .{ }^{15}$ Amplification reactions were carried out in a total volume of $20 \mu \mathrm{l}$, using 100 to $200 \mathrm{ng}$ genomic DNA or $1 \mathrm{~mm}^{2}$ filter paper blood spot, $200 \mu \mathrm{mol} / 1 \mathrm{dNTPs}, 20$ pmol of each unlabelled primer, $0.2 \mathrm{pmol}$ of one primer end labelled with $\gamma^{32} \mathrm{P}$-ATP, 50 $\mathrm{mmol} / 1 \mathrm{KCl}, 10 \mathrm{mmol} / 1$ Tris $\mathrm{HCl}$ (pH 9.0), $0.1 \%$ Triton X-100, $1.5 \mathrm{mmol} / 1 \mathrm{MgCl}_{2}$, and 1U Taq polymerase. Samples were denatured at $96^{\circ} \mathrm{C}$ for five minutes, followed by 35 cycles of 30 seconds at $94^{\circ} \mathrm{C}$, one minute at $50^{\circ} \mathrm{C}$, and one minute at $72^{\circ} \mathrm{C}$, with a final 10 minute extension stage at $72^{\circ} \mathrm{C}$. DNA free controls were run with each batch to detect DNA contamination of reagent solutions. PCR products were heat denatured at $96^{\circ} \mathrm{C}$ in $95 \%$ formamide, and resolved by electrophoresis on $6 \%$ polyacrylamide $/ 7 \mathrm{~mol} / 1$ urea denaturing gels run at $45 \mathrm{~W}$ for two hours. The gels were dried and autoradiographed. The alleles were numbered as in the original description of this polymorphism, whereby the most common allele is designated A4. ${ }^{15} \mathrm{~A}$ sample from a single subject of genotype A4/A7 was included on every gel to ensure consistency of allele assignment. 
Table 3 Maternal and fetal allele frequencies for three diallelic polymorphisms in the $A T_{I}$ receptor gene for 80 normotensive (NT) and 41 pre-eclamptic (PE) pregnancies. The mutant allele frequency is shown in each case

\begin{tabular}{|c|c|c|c|c|c|c|}
\hline \multirow[b]{3}{*}{ Location } & \multirow[b]{3}{*}{ Polymorphism } & \multicolumn{5}{|c|}{ Allele frequency } \\
\hline & & \multicolumn{2}{|c|}{ Maternal } & \multicolumn{2}{|l|}{ Fetal } & \multirow{2}{*}{$\begin{array}{l}95 \% C I \\
f[P E]-f[N T]\end{array}$} \\
\hline & & $N T$ & $P E$ & $N T$ & $P E$ & \\
\hline Coding region & $573 \mathrm{C}$ to $\mathrm{T}$ & 0.47 & 0.43 & 0.42 & 0.52 & -0.09 to 0.29 \\
\hline Coding region & $1062 \mathrm{~A}$ to $\mathrm{G}$ & 0.11 & 0.09 & 0.08 & 0.06 & -0.11 to 0.07 \\
\hline $3^{\prime}$ untranslated & $1166 \mathrm{~A}$ to $\mathrm{C}$ & 0.27 & 0.29 & 0.30 & 0.25 & -0.22 to 0.12 \\
\hline
\end{tabular}

$f[\mathrm{PE}]-f[\mathrm{NT}]=95 \%$ confidence intervals for difference in frequencies of mutant alleles in fetal samples from pre-eclamptic and normotensive pregnancies.

Table 4 Fetal and maternal AT, receptor gene dinucleotide repeat allele frequencies from 80 normotensive and 41 pre-eclamptic pregnancies

\begin{tabular}{lccccccccc}
\hline Allele & $A 1$ & $A 2$ & $A 3$ & $A 4$ & $A 5$ & $A 6$ & $A 7$ & $A 8$ & $A 9$ \\
\hline $\begin{array}{l}\text { Fetal } \\
\text { Normotensive }\end{array}$ & 0.03 & 0.14 & 0.21 & 0.41 & 0.04 & 0.06 & 0.06 & 0.05 & 0 \\
$\begin{array}{l}\text { Pre-eclamptic } \\
0.02\end{array}$ & 0.10 & 0.16 & 0.51 & 0.05 & 0.04 & 0.12 & 0 & 0 \\
$\begin{array}{l}\text { Maternal } \\
\text { Normotensive }\end{array}$ & 0.03 & 0.13 & 0.16 & 0.46 & 0.06 & 0.07 & 0.06 & 0.03 & $<0.01$ \\
Pre-eclamptic & 0.02 & 0.15 & 0.11 & 0.40 & 0.11 & 0.07 & 0.12 & 0.01 & 0 \\
\hline
\end{tabular}

STATISTICAL METHODS

Allele and genotype frequencies from preeclamptic and normotensive pregnancies were compared using the chi squared test with Yates's correction or Fisher's exact test where appropriate. Distortion of dinucleotide repeat allele transmission from heterozygous mothers was assessed by testing of informative pregnancies, that is, those in which the mother was heterozygous and the fetal genotype differed from the maternal genotype, in a two step analysis. For each dinucleotide repeat allele, the number of alleles transmitted in informative preeclamptic and normotensive pregnancies was compared using a two tailed Fisher's exact test. Significance levels were adjusted for testing of multiple alleles using the Bonferoni correction. For any allele for which this initial test showed significant distortion of transmission, the results were further examined in pre-eclamptic and normotensive pregnancies individually. For each allele, $\mathrm{Ai}$, the probability of $\mathrm{Ai}$ being transmitted to the fetus conditional on the pregnancy being informative was calculated as follows: estimates of allele frequencies, $\mathrm{Pi}$, were obtained by pooling results of maternal genotyping from normotensive and pre-eclamptic pregnancies. Consider a mother who is heterozygous for a specific Ai allele, and of genotype $\mathrm{Ai} / \mathrm{Aj}$, where $\mathrm{Aj}$ is any allele other than $\mathrm{Ai}$, with frequency $\mathrm{Pj}$. The probability that she has the specific allele $\mathrm{Aj}$, and is thus $\mathrm{Ai} / \mathrm{Aj}$, is $\mathrm{Pj} /(1-\mathrm{Pi})$. If such a mother passes on the Ai allele, with probability 0.5 , the probability that the pregnancy is informative (that is, the fetus has a paternal allele other than $\mathrm{Aj}$ ) is $1-\mathrm{Pj}$. The total probability that a heterozygous female passes on $\mathrm{Ai}$ and is informative is thus

$$
\frac{0.5\left(\sum_{j \neq i} \operatorname{Pj}(1-P j)\right)}{(1-\mathrm{Pi})}=a
$$

If the mother passes on the $\mathrm{Aj}$ allele, with probability 0.5 , the probability that the pregnancy is informative (that is, the fetus has a paternal allele other than $\mathrm{Ai}$ ) is $1-\mathrm{Pi}$ for all $\mathrm{j}$. Thus the probability that an $\mathrm{A} i / \mathrm{Aj}$ heterozygote passes on $\mathrm{Aj}$ and is informative is $0.5(1-\mathrm{Pi})=b$.

The total probability that a maternal-fetal pair is informative is thus $a+b$ and the probability of a mother who is heterozygous for $\mathrm{Ai}$ transmitting $\mathrm{Ai}$, conditional on the pregnancy being informative, is $a /(a+b)$. The observed number of alleles transmitted was compared with the expected transmission, based on the estimated conditional probability, using a binomial exact test.

\section{Results}

There were no significant differences between normotensive and pre-eclamptic groups in the allele or genotype frequencies of diallelic polymorphisms, or in the distribution of dinucleotide repeat alleles, in either fetal or maternal samples (tables 3 and $4, p>0.05$ ). The results of maternal genotyping have been reported previously ${ }^{13}$; they are reproduced here for ease of reference.

The highly polymorphic nature of the dinucleotide repeat polymorphism permitted tracking of allele transmission in a proportion of maternal-fetal pairs; $51 \%$ normotensive $(n=41)$ and $66 \%$ pre-eclamptic $(n=27)$ pregnancies were informative. Results are shown in table 5. One allele, designated A4, showed significant differences in allele transmission when normotensive pregnancies were compared with pre-eclamptic pregnancies (nominal significance $p<0.001$, two tailed Fisher's exact test; corrected for testing of multiple alleles $\mathrm{p}<0.01)$. The estimated probability of transmission of the A4 allele, conditional on the pregnancy being informative, was 0.615 . In the pre-eclamptic group, transmission of the A4

Table 5 Number (proportion) of AT, receptor gene dinucleotide repeat alleles transmitted from mother to fetus in 41 informative normotensive pregnancies and 27 pre-eclamptic pregnancies

\begin{tabular}{|c|c|c|c|c|c|c|c|c|}
\hline \multirow[b]{2}{*}{ Allele } & \multicolumn{4}{|c|}{ Normotensive women } & \multicolumn{4}{|c|}{ Pre-eclamptic women } \\
\hline & $\begin{array}{l}\text { Homo- } \\
\text { zygous }\end{array}$ & $\begin{array}{l}\text { Hetero- } \\
\text { zygous }\end{array}$ & $\begin{array}{l}\text { Informative } \\
\text { pregnancies }\end{array}$ & $\begin{array}{l}\text { Maternal-fetal } \\
\text { transmission }\end{array}$ & $\begin{array}{l}\text { Homo- } \\
\text { zygous }\end{array}$ & $\begin{array}{l}\text { Hetero- } \\
\text { zygous }\end{array}$ & $\begin{array}{l}\text { Informative } \\
\text { pregnancies }\end{array}$ & $\begin{array}{l}\text { Maternal-fetal } \\
\text { transmission }\end{array}$ \\
\hline A1 & 0 & 5 & 4 & $3(0.75)$ & 0 & 2 & 2 & $0(0)$ \\
\hline A2 & 2 & 17 & 11 & $5(0.45)$ & 1 & 10 & 10 & $2(0.20)$ \\
\hline A3 & 3 & 19 & 14 & $11(0.79)$ & 0 & 9 & 7 & $4(0.57)$ \\
\hline A4 & 17 & 39 & 26 & $8(0.31)$ & 5 & 23 & 18 & $15(0.83)^{\star}$ \\
\hline A5 & 0 & 10 & 9 & $3(0.33)$ & 2 & 5 & 5 & $1(0.20)$ \\
\hline A6 & 1 & 9 & 6 & $3(0.50)$ & 0 & 6 & 5 & $1(0.20)$ \\
\hline A7 7 & 0 & 10 & 8 & $5(0.63)$ & 1 & 8 & 6 & $4(0.67)$ \\
\hline A8 & 0 & 4 & 3 & $3(1.00)$ & 0 & 1 & 1 & $0(0)$ \\
\hline A9 & 0 & 1 & 1 & $0(0)$ & 0 & 0 & 0 & $0(0)$ \\
\hline
\end{tabular}

*Significant excess of A4 alleles transmitted from mother to fetus in pre-eclamptic compared with normotensive pregnancies; $\mathrm{p}<0.001$ (two tailed Fisher's exact test); $\mathrm{p}<0.01$, corrected for testing of multiple alleles. 
allele from mother to fetus exceeded the expected probability $(p=0.04$, binomial exact test), while in the normotensive group, the A4 allele was transmitted from mother to fetus less frequently than expected $(\mathrm{p}<0.005)$.

Of the diallelic polymorphisms, only that at nucleotide 573 provided a sufficient number of heterozygous pregnancies for meaningful statistical analysis of allele transmission (21 pre-eclamptic, 40 normotensive). The probability of a heterozygous mother transmitting the variant $573 \mathrm{~T}$ allele conditional on the pregnancy being informative was 0.454 . The $573 \mathrm{~T}$ allele was transmitted from mother to fetus in nine of 13 informative pre-eclamptic pregnancies, marginally more frequently than expected $(p=0.07)$, and in five of 23 informative normotensive pregnancies, significantly less frequently than expected $(p=0.02)$. These observations complement those relating to transmission of the dinucleotide repeat alleles, as the A4 allele and the 573T allele are in partial positive linkage disequilibrium. ${ }^{13}$

\section{Discussion}

This study provides preliminary evidence that in pre-eclampsia there is distortion of transmission from mother to fetus of an $\mathrm{AT}_{1}$ receptor allele. The dinucleotide repeat allele designated A4 is transmitted in excess in preeclamptic pregnancies. A similar trend was observed in the smaller number of pregnancies informative for transmission of the $573 \mathrm{~T}$ variant. As a corollary of this observation, these alleles are transmitted less frequently than expected in normotensive pregnancies. Dinucleotide repeats are widely distributed in the genome, and may be involved in crossover of genetic material during meiosis. ${ }^{16}$ There is no evidence that variation in the number of repeats has functional effects, and their main value to molecular geneticists is as highly polymorphic allelic markers. The $\mathrm{C}$ to $\mathrm{T}$ mutation at nucleotide 573 similarly has no known functional effects; although it lies within the coding region of the gene, it does not alter the encoded amino acid residue. ${ }^{14}$ Both the $\mathrm{A} 4$ allele and the $573 \mathrm{~T}$ allele may therefore be acting as markers for a linked mutation at a functional site. In our earlier study of the maternal $\mathrm{AT}_{1}$ receptor genotypes in this group of subjects, normotensive pregnant women possessing either one or two copies of the 573T variant had lower levels of $\mathrm{AT}_{1}$ surface receptors, measured as platelet AII binding, than women homozygous for the 573C allele. ${ }^{13}$ This suggests that the polymorphism at nucleotide 573 is in linkage disequilibrium with a variant which affects $\mathrm{AT}_{1}$ receptor expression in platelets. Whether vascular and placental $\mathrm{AT}_{1}$ receptor expression are similarly lower in association with the 573T variant is at present unknown.

Altered $\mathrm{AT}_{1}$ receptor expression at the maternal-fetal interface could potentially influence placental haemodynamics. Vascular response elements modulating maternal blood flow to the placenta lie in the uterine, radial, and basal arteries. ${ }^{17}$ The spiral arteries normally lose their pressor responsiveness during trophoblast invasion, although they retain the ability to constrict in pre-eclampsia, where invasion of their myometrial segment during placentation is incomplete. ${ }^{18}$ Within the placenta, vascular response elements lie entirely on the fetal side of the circulation. The major resistance vessels are the previllous arterioles. The effects of angiotensin II in the control of placental circulation are complex. Angiotensin II causes constriction of the resistance vessels ${ }^{19}$ while stimulating placental secretion of vasodilatory prostaglandins. ${ }^{9}$ Reduced placental $\mathrm{AT}_{1}$ receptor expression may be a primary factor in impaired placental prostaglandin secretion in pre-eclampsia, resulting in inadequate placental vasodilation and placental ischaemia, followed in due course by the appearance of the pre-eclamptic phenotype in the mother.

More speculative are the possible effects of reduced $\mathrm{AT}_{1}$ receptor expression on trophoblast invasion and placentation. The factors determining successful implantation and placentation are incompletely understood. Angiotensin II has been shown to induce neovascularisation when implanted into rabbit cornea ${ }^{20}$ and has a dose dependent angiogenic effect when applied to chick chorioallantoic membrane. ${ }^{21}$ While not conclusive in themselves, these observations indicate that angiotensin II does at least merit serious consideration as a factor required for successful placentation. Low trophoblast responsiveness to angiotensin II, resulting from low $\mathrm{AT}_{1}$ receptor expression, could then lead to impaired placentation and pre-eclampsia.

Reduced transmission of the A4 allele in normotensive pregnancies is difficult to explain. Statistically, this is more significant than the increased A4 allele transmission in preeclamptic pregnancies, although this may be partly because of the larger number of informative pregnancies in the normotensive group $(n=26)$ compared with the preeclamptic group $(n=18)$. It is worth noting that the significance values are highly sensitive to the calculated probability of allele transmission conditional on the pregnancy being informative, which is in turn dependent on estimated allele frequencies. As the value of the conditional probability of allele transmission tends towards the unconditional probability of 0.5 , the observed deficit of $\mathrm{A} 4$ allele transmission in normotensive pregnancies becomes less statistically significant, while the excessive allele transmission in the pre-eclamptic group becomes more significant.

In conclusion, we present preliminary evidence that in a subgroup of pregnancies there is distortion of transmission of an $\mathrm{AT}_{1}$ receptor allele variant, which appears to be associated with pre-eclampsia. These observations require independent confirmation. Increased maternal-fetal transmission of an $\mathrm{AT}_{1}$ receptor allele in pre-eclampsia is consistent with a purely fetal genetic contribution; alternatively, susceptibility to pre-eclampsia may require both mother and fetus to express the same AT receptor allele. Possible explanatory mechanisms are suggested by the observation that this variant is associated with relatively low receptor expression on the platelets of normotensive 
pregnant women. If the levels of receptor expression in the trophoblast and placenta are similarly genetically determined, possession of this allele by the fetus may result in relative refractoriness to the effects of angiotensin II, affecting placentation, placental prostacyclin secretion, and placental haemodynamics.

We wish to thank Dr R Pollitt and Dr D Curtis for providing access to samples stored in the Trent Regional Neonatal Screening Unit archive. Financial assistance from the Medical Research Council, Trent Regional Health Authority, and Nottingham Hospital Trustees is gratefully acknowledged.

1 Chesley LC, Cooper DW. Genetics of hypertension in pregnancy: possible single gene control of pre-eclampsia and Obstet Gynaecol 1986;93:898-908.

2 Arngrimsson R, Biornsson S, Geirsson RT, Bjornsson $H$ Arngrimsson R, Bjornsson S, Geirsson RT, Bjornsson H,
Walker JJ, Snaedal G. Genetic and familial predisposition Walker JJ, Snaedal G. Genetic and familial predisposition to eclampsia and pre-eclampsia in

3 Liston WA, Kilpatrick DC. Is susceptibility to pre-eclampsia conferred by homozygosity for the same single recessive gene in mother and fetus? Br $\mathcal{F}$ Obstet Gynaecol 1991;98: 1079-86.

4 Pijnenborg R, Anthony J, Davey DA, et al. Placental bed spiral arteries in the hypertensive disorders of pregnancy. $\mathrm{Br} f$ Obstet Gynaecol 1991;98:648-55.

5 Roberts JM, Redman CWG. Pre-eclampsia: more than pregnancy-induced hypertension. Lancet 1993;341:144754.

6 Kalenga MK, de Gasparo M, de Hertogh R, Whitebread S, Vankrieken L, Thomas K. Les récepteurs de l'angiotensine II dans le placenta humain sont de type AT1. Reprod Nutr Dev 1991;31:257-67.

7 Knock GA, Sullivan MHF, McCarthy A, Elder MG, Polak JM, Wharton J. Angiotensin II (AT1) vascular binding sites in human placentae from normal-term, pre-eclamptic an growth retarded pregnancies. $f$ Pharmacol Exp Ther 1994;271:1007-15.

8 Brar HS, Kjos SL, Dougherty W, Do YS, Tam HB, Hsueh WA. Increased fetoplacental active renin production in pregnancy-induced hypertension. Am $\mathcal{F}$ Obstet Gynecol 1987;157:363-7.
9 Glance DG, Elder MG, Myatt L. Prostaglandin production and stimulation by angiotensin II in the isolated perfused and stimulation by angiotensin II in the isolated perfused human plac

10 Jaiswal N, Tallant EA, Jaiswal RK, Diz DI, Ferrario CM. Differential regulation of prostaglandin synthesis by angiotensin peptides in porcine aortic smooth muscle cells: subtypes of angiotensin receptors involved. 7 Pharmacol Exp Ther 1993;265:664-73.

11 Fitzgerald DJ, Entman SS, Mulloy K, FitzGerald GA Decreased prostacyclin biosynthesis preceding the clinical manifestations of pregnancy-induced hypertension. Circulation 1987;75:956-63.

12 Gant NF, Daley GL, Chand S, Whalley PJ, MacDonald PC. A study of angiotensin II pressor response throughout primigravid pregnancy. $\mathcal{F}$ Clin Invest 1973;52:2682-9.

13 Morgan L, Crawshaw S, Baker PN, Edwards R, Broughton Pipkin F, Kalsheker N. Functional and genetic studies of the angiotensin II type 1 receptor in pre-eclamptic and normotensive pregnant women. $\mathcal{F}$ Hypertens 1997;15:138996.

14 Bonnardeaux A, Davies E, Jeunemaitre X, et al. Angiotensin II AT1 receptor gene polymorphisms in human essential hypertension. Hypertension 1994;24:63-9.

15 Davies E, Bonnardeaux A, Lathrop GM, Corvol P, Clause E, Soubrier F. Angiotensin II (type-1) receptor locus: CA repeat polymorphism and genetic mapping. Hum Mol Genet 1994;3:838.

16 Jeffreys AJ, Allen MJ, Armour JAL, et al. Mutation processes at human minisatellites. Electrophoresis 1995;16:1577-85.

17 Zuspan FP. Abnormal placentation in hypertensive disorders of pregnancy. In: Laragh $\mathrm{JH}$, Brenner $\mathrm{BM}$, eds. Hypertension: pathophysiology, diagnosis and management. New York: Raven Press, 1990:1779-88.

18 Myatt L. Control of vascular resistance in the human placenta. Placenta 1992;13:329-41.

19 Wilkes BM, Krim E, Mento PF. Evidence for a functional renin-angiotensin system in full-term fetoplacental unit. Am F Physiol 1985;249:E366-73.

20 Fernandez LA, Twickler J, Mead A. Neovascularization 5 prod

21 Le Noble FAC, Hekking JWM, Vanstraaten HWM, Slaa DW, Boudier HAJS. Angiotensin-II stimulates angiogenesis in the chorio-allantoic membrane of the chick embryo. Eur $\mathcal{F}$ Pharmacol 1991;195:305-6. 